\title{
EDITORIAL
}

\section{El motor del entusiasmo en la investigación y la docencia}

Se acaban de cumplir cien años de la creación del Centro de Investigaciones Biológicas o Instituto Cajal ${ }^{1}$, del cual fue nombrado director don Santiago Ramón y Cajal, quien ocupó el cargo hasta 1934. Aunque haya pasado un siglo desde el acontecimiento, las actitudes y los principios que regían la actividad investigadora y docente de nuestro premio Nobel siguen teniendo plena vigencia. Fijémonos ahora brevemente en una de estas actitudes: su entusiasmo.

Ramón y Cajal llegó a decir: El explorador de la Naturaleza debe considerar la investigación como un sport incomparable, en el cual todo, desde los procederes técnicos hasta la elaboración doctrinal, constituye un perenne manantial de gratas satisfacciones. Quien en presencia de un arduo problema no sienta crecer su entusiasmo, a medida que el entendimiento redobla sus esfuerzos; quien, al aproximarse el solemne momento del fiat lux, impacientemente esperado, no tenga el alma inundada por la emoción precursora del placer, debe abandonar las empresas científicas, porque la Naturaleza no otorga sus favores a los fríos de condición, y la frialdad es a menudo inequívoco signo de impotencia ${ }^{2}$.

Podemos afirmar que el entusiasmo es el motor no declarado tanto de la actividad investigadora como de la actividad docente: es la fuente de energía que predispone a dedicar tiempo y esfuerzo a tareas que otros muchos considerarían ingratas, y que anima a superar dificultades que otros tacharían como insalvables. La necesidad de entusiasmo se aplica al investigador, al alumno, al profesor y a todos cuantos integramos la Universidad. Quien lo pierde se jubila anticipadamente, y quien lo olvida se apunta a engrosar la lista de los descontentos por sistema.

La Facultad de Ciencias Biológicas y Ambientales de la Universidad de León ha optado por el cultivo del entusiasmo, muestra de lo cual es la apuesta por la revista AmbioCiencias, que ya va por la edición de su décimo octavo número, y que a lo largo de este año ha renovado su Consejo de Redacción. Agradezco en nombre de la Facultad y del Consejo de Redacción entrante el buen hacer y la dedicación del equipo anterior en general, y del Dr. Juan Manuel Nieto Nafría, su anterior director, en particular.

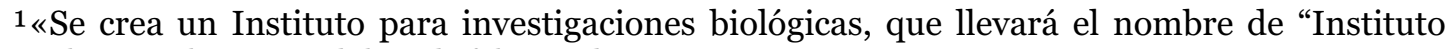
Cajal"» (Real Decreto del 20 de febrero de 1920).

2 Discurso de ingreso del Sr. D. Santiago Ramón y Cajal leído 5 de diciembre de 1897 ante la Real Academia de Ciencias Exactas, Físicas y Naturales, sobre el tema Fundamentos racionales y condiciones técnicas de la investigación biológica.
} 
Es fácil comprobar que el entusiasmo y la pasión por la ciencia y la docencia es el denominador común de los once artículos que se despliegan a continuación, tan diversos por lo demás. Esta diversidad proviene de la procedencia de sus autores, ya que algunos de ellos son alumnos de grado o máster, o bien profesores o investigadores de esta Facultad, mientras que otros son profesionales egresados de nuestras aulas y, por último, otros más son investigadores, vinculados de una manera u otra a nuestra Universidad, y que han desarrollado y siguen llevando a cabo actividades científicas relevantes.

Los artículos son diversos también en cuanto a la procedencia geográfica de las investigaciones: la mayoría de ellas provienen de laboratorios de la Universidad de León, pero unos cuantos artículos se centran en actividades desarrolladas en países allende nuestras fronteras, como Italia, Venezuela o Estados Unidos.

Por último, los artículos son también diversos en cuanto a su temática, ya que se centran en aspectos concretos de la biomedicina, la protección del patrimonio, la biología de las plantas, la piscicultura, la biología sintética y la biotecnología, o la innovación docente.

No podía faltar en este año 2020 un artículo sobre los coronavirus, en estos tiempos de pandemia que estamos padeciendo, y que tanto han interferido con nuestras tareas docentes e investigadoras (y a la cual, dicho sea de paso, hemos tenido que enfrentarnos derrochando creatividad y entusiasmo). El artículo se inscribe en la sección $A$ fondo, y ha sido elaborado por los doctores Pedro $\mathrm{Ru}-$ bio y Ana Carbajal, investigadores de nuestra Universidad, relevantes en este campo.

Otro de los artículos singulares de este número es el firmado por el Dr. Elías F. Rodríguez Ferri, con ocasión del cuarenta aniversario de nuestra Facultad, en este caso evocando al Dr. Santos Ovejero, que tanto tuvo que ver con la creación de nuestro centro.

Y para terminar como hemos empezado - evocando un centenario- cabe destacar el artículo del Dr. Estanislao Luis Calabuig como homenaje al escritor y periodista Miguel Delibes Setién con ocasión del centenario de su nacimiento.

En nombre del Consejo de Redacción actual pongo de manifiesto el compromiso común por hacer crecer la llama del entusiasmo en AmbioCiencias, siguiendo el estímulo de D. Santiago Ramón y Cajal. Quedamos a disposición de quienes se acerquen a estas páginas, para satisfacer sus demandas y seguir apostando por una revista comprometida con la divulgación científica y la innovación docente.

José Luis Acebes

Director de Ambiociencias 